\title{
A dimensão regional da política de educação em saúde no Rio Grande do Sul
}

\author{
Maria Raquel Pilar Steyer \\ Universidade Santa Cruz do Sul \\ Marco André Cadoná \\ Universidade Santa Cruz do Sul \\ Leni Dias Weigelt \\ Universidade Santa Cruz do Sul
}

Recebido: 30/11/2016 Versão revisada (entregue): 27/03/2018 Aprovado: 17/06/2018

\begin{abstract}
Resumo
O presente artigo analisa o processo de regionalização da Comissão de Integração EnsinoServiço (CIES) na construção de uma política regional pela qual militantes da educação em saúde têm se mobilizado. A mobilização busca não apenas dar visibilidade à política de educação permanente em saúde, mas também garantir o comprometimento do poder público na implementação dessas políticas em âmbito regional. Quanto aos procedimentos metodológicos, eles se basearam na análise de documentos relacionados às legislações vinculadas à política de educação permanente em saúde e à estruturação da CIES, bem como de documentação relativa às atividades da CIES na Região 28 de Saúde, no Rio Grande do Sul, no período entre 2007 e 2014. Como resultado, verificou-se que, a partir da experiência histórica da CIES na referida região, os participantes comprometidos com esse campo de políticas públicas puderam se colocar em um importante espaço de execução de políticas regionais de educação permanente em saúde, potencializando-o enquanto espaço político e de militância na construção de políticas públicas.
\end{abstract}

Palavras-chave | dimensão regional; educação em saúde; políticas públicas; Rio Grande do Sul.

Código JEL |H75; I18; R12.

\section{THE REGIONAL DIMENSION OF THE EDUCATION POLICY IN HEALTH IN RIO GRANDE DO SUL}

\section{Abstract}

This article presents an analysis about the process of regionalization of the Education and Service Integration Commission (CIES) in the construction of a regional policy. Whereby, health education activists mobilize not only to give visibility to the policy of permanent education in health, also, to ensure the commitment of the public power in the implementation of these policies at the regional level. As for the methodological procedures, these included the analysis of documents related to the legislation on the policy of permanent education in health 
and the structuring of CIES. Also, the analysis of documentation that registered the activities of CIES in Health Region 28, South region in Rio Grande do Sul, between 2007 and 2014. As a result, it was verified that from the historical experience of CIES in the Region, the participants committed to this field of public policies could place themselves in an important space of militancy and execution of regional policies of education permanent health. It, potentializes this space as a political space and militancy in the construction of public policies.

Keywords | Education in health; public policies; regional dimension; Rio Grande do Sul.

JEL-Code | H75; I18; R12.

\section{LA DIMENSIÓN REGIONAL DE LA POLÍTICA DE EDUCACIÓN EN SALUD EN RIO GRANDE DO SUL}

\section{Resumen}

El presente artículo analiza el proceso de regionalización de la Comisión de Integración Enseñanza-Servicio (CIES) en la construcción de una política regional por la cual militantes de la educación en salud se han movilizado. La movilización no sólo busca dar visibilidad a la política de educación permanente en salud, sino también garantizar el compromiso del poder público en la implementación de esas políticas en el ámbito regional. Los procedimientos metodológicos se basaron en el análisis de documentos relacionados a las legislaciones vinculadas a la política de educación permanente en salud y la estructuración de la CIES, así como documentos relacionados a las actividades de la CIES en la Región 28 de Salud, en Rio Grande do Sul, en el período entre 2007 y 2014. Como resultado, se verificó que a partir de la experiencia histórica de la CIES en la región, los participantes comprometidos con ese campo de políticas públicas pudieron colocarse en un importante espacio de ejecución de políticas regionales de educación permanente en salud, potenciándolo como un espacio político y de militancia en la construcción de las políticas públicas.

Palabras-clave | dimensión regional; educación en salud; políticas públicas; Rio Grande do Sul.

Código JEL | H75; I18; R12.

\section{Introdução}

A política pública de educação permanente em saúde ganhou maior importância no Brasil principalmente a partir dos anos 1990, quando foram colocados diferentes desafios relacionados ao trabalho e aos trabalhadores em saúde, em função da criação do SUS (Sistema Único de Saúde). Aos poucos, foi amadurecendo um projeto de educação permanente em saúde assentado na visão de que a implantação do SUS requeria um trabalhador de saúde comprometido, engajado, com habilidades para o trabalho em equipe, com uma visão ampliada do conceito de saúde, participativo em seu processo de trabalho (PAIM, 2008).

Durante a década de 1990 e início dos anos 2000, diferentes estratégias de formação no e para o trabalho em saúde foram definidas (no âmbito da implantação da Estratégia de Saúde da Família, em 1994, ou, então, na criação da 
Política Nacional de Humanização, em 2003), até que, em 2006, através da divulgação, pelo Ministério da Saúde, do Pacto pela Saúde, os espaços regionais foram consolidados pelas legislações do campo da saúde como espaço de decisão na implantação da política de educação permanente em saúde (BATISTA; GONÇALVES, 2011).

Naquele contexto, ao final do processo de discussão sobre o Pacto pela Saúde 2006, o Ministério da Saúde "republicou", em 2007, a Portaria n. 198, a partir da qual três mudanças básicas foram estabelecidas: a) alteração da política de saúde, atribuindo-se maior "protagonismo" aos Colegiados de Gestão Regional; b) a descentralização dos recursos financeiros, antes sob a gestão do Ministério da Saúde; c) a "vinculação das ações de desenvolvimento dos trabalhadores do SUS aos planos de Educação Permanente em Saúde, nos âmbitos municipal, regional ou estadual" (BATISTA; GONÇALVES, 2011, p. 889).

Nessa perspectiva, o Ministério da Saúde publicou, em agosto de 2007, a Portaria n. 1.996, que dispôs "sobre as diretrizes para a implementação da Política Nacional de Educação Permanente em Saúde" (BRASIL, 2007). Através daquela Portaria, o Ministério da Saúde afirmou a necessidade de uma política nacional comprometida com "as especificidades regionais" e "a superação das desigualdades regionais", atribuindo a condução regional das políticas de educação permanente em saúde aos "Colegiados de Gestão Regional", com a participação das “Comissões de Integração Ensino-Serviço (CIES)” (BRASIL, 2007).

De acordo com a Portaria n. 1.996, aos Colegiados de Gestão Regional compostos pelos "gestores de saúde do conjunto de municípios de uma determinada região de saúde e por representantes do(s) gestor(es) estadual(ais)" cabe "instituir processo de planejamento regional para a Educação Permanente em Saúde que defina as prioridades, as responsabilidades de cada ente e o apoio para o processo de planejamento local" (BRASIL, 2007).

Embora a Portaria n. 1.996 tenha atribuído papel proeminente aos Colegiados de Gestão no planejamento e na execução de uma política regional de educação permanente em saúde, a mesma Portaria atribuiu grande importância para as CIES. Além de serem constituídas por representações dos gestores de saúde, das instituições que atuam na área de formação e desenvolvimento de pessoal para o setor de saúde, dos trabalhadores em saúde, dos movimentos sociais e/ou conselhos de saúde de uma dada região de saúde, as CIES, de acordo com a Portaria n. 1.996, têm um espaço político (regional) estratégico na formulação, na condução e no desenvolvimento da Política de Educação Permanente em Saúde.

Isso ficou evidenciado no artigo $6^{\circ}$ da Portaria n. 1.996, que definiu as atribuições das CIES: "apoiar e cooperar tecnicamente com os Colegiados de Gestão Regional para a construção dos Planos Regionais de Educação Permanente em Saúde"; "articular instituições para propor, de forma coordenada, estratégias de intervenção no campo da formação e desenvolvimento dos trabalhadores"; 
“incentivar a adesão cooperativa e solidária de instituições de formação e desenvolvimento dos trabalhadores de saúde aos princípios, à condução e ao desenvolvimento da Educação Permanente em Saúde, ampliando a capacidade pedagógica em toda a rede de saúde e educação"; "contribuir para o acompanhamento, o monitoramento e a avaliação das ações e estratégias de Educação Permanente em Saúde implementada"; "apoiar e cooperar com os gestores na discussão sobre Educação Permanente em Saúde, na proposição de intervenções nesse campo e no planejamento e desenvolvimento de ações que contribuam para o cumprimento das responsabilidades assumidas nos respectivos Termos de Compromisso de Gestão” (BRASIL, 2007).

É a partir dessa contextualização histórica da discussão de uma política de educação permanente em saúde no Brasil, com ênfase ao caráter regional que a mesma tomou a partir da primeira década deste século XXI, que se pretende analisar o espaço político de participantes da CIES (Comissão de Integração Ensino-Serviço) enquanto militantes políticos na construção de uma política de educação permanente em saúde na Região 28 de Saúde no Rio Grande do Sul ${ }^{1}$. A análise, assim, destaca os conflitos e os embates implicados na discussão sobre políticas públicas de educação em saúde, mas, principalmente, a importância dos participantes da CIES na discussão sobre educação em saúde na região, sobretudo na articulação política junto aos municípios, visando concretizar ações educativas dirigidas aos profissionais de saúde.

Sob o ponto de vista metodológico, o artigo é resultado de uma investigação que compreendeu duas frentes de trabalho: por um lado, o levantamento e a análise de documentos (legislação, em especial) relacionados à política de educação permanente em saúde e à estruturação das Comissões de Integração EnsinoServiço; por outro lado, a análise de documentos que registram as atividades da CIES da Região 28 de Saúde no período entre 2007 e 2014 (atas de reuniões; relatórios de atividades).

É importante ponderar, ainda, que o estudo considera a participação sociopolítica a partir de uma "escala de atuação", a escala regional. Nesse sentido, pressupõe-se que a região é um "território de militância", ou seja, um espaço/tempo que condiciona a própria construção de sujeitos sociopolíticos que, uma vez constituídos, procuram interferir nos processos decisórios que, afinal, definem condições de desenvolvimento numa determinada região. De forma mais específica, a 28 $8^{a}$ Região de Saúde (institucionalizada enquanto Região onde se discutem ações de educação em saúde) é expressão da existência de um território, referência a partir da qual indivíduos, coletividades, movimentos sociais,

\footnotetext{
${ }^{1}$ A Região 28 de Saúde é constituída por treze municípios, quais sejam: Santa Cruz do Sul, Gramado Xavier, Herveiras, Sinimbu, Mato Leitão, Candelária, Vale do Sol, Vera Cruz, Venâncio Aires, Passo do Sobrado, Vale Verde, Rio Pardo e Pantano Grande.
} 
instituições sociais, governos municipais etc. se mobilizam, agem politicamente com o intuito de que seus interesses possam ser representados na definição das políticas públicas (regionais) no campo da saúde.

\section{A região como território de militância: uma análise da importância da militância na construção de políticas públicas em saúde}

No Brasil, a saúde como um direito universal e um dever do Estado somente foi institucionalizado na Constituição Federal de 1988, quando foi criado o SUS (Sistema Único de Saúde). O SUS, é importante destacar, é uma das principais políticas públicas de inclusão social executada no Brasil a partir do processo de democratização (década de 1980), representando, em termos constitucionais, a afirmação política do compromisso do Estado brasileiro com a democratização da saúde no País, integrando diferentes escalas de atuação estatal (nacional, estadual, regional, municipal), mas, fundamentalmente, garantindo a participação da sociedade no processo de construção da política pública.

Ao assegurar, dentre os seus princípios e diretrizes, “a participação da população por meio de organizações representativas na formulação das políticas e no controle das ações em todos os níveis" (Art. 204), o SUS instituiu, no âmbito das políticas públicas, a participação e o controle das ações do Estado como eixo fundamental na construção das políticas de saúde no País (BRASIL, 1988). A partir de então, o maior desafio passou a ser a regulamentação desses processos, a fim de efetivar a articulação da sociedade civil, estabelecer os mecanismos jurídicos legais necessários à descentralização das políticas públicas e garantir a efetividade da participação social e de maior democratização do processo decisório. Destaque-se, portanto, que a partir da década de 1990 o Brasil tem uma política de estado na área de saúde que consagrou alguns princípios fundamentais à natureza das políticas públicas de saúde no País; dentre os quais, a "participação da população" e a "regionalização das ações" de forma integrada, destacando-se o espaço regional como um espaço que, pela própria institucionalidade das políticas públicas de saúde a partir da criação do SUS, ganhou maior importância.

Foi com base no princípio da regionalização da política que, já a partir da primeira década de 2000, um processo mais efetivo de criação de Regiões de Saúde teve início, com a apresentação em documentos oficiais, com o estabelecimento de pactos intergovernamentais para responder às demandas crescentes dos cidadãos por serviços de saúde mais resolutivos e de melhor qualidade. Nessa direção, foi instituído um conjunto de leis e de portarias determinando regras e mecanismos desse processo em todo o território nacional, merecendo destaque, entre outras e além da Constituição Federal, as Leis Orgânicas da Saúde n. 8.080 e n. 8.142, ambas de 1990, as Normas Operacionais Básicas de 1993 e de 1996, as Normas 
Operacionais de Assistência à Saúde (01/2001 e 01/2002), o Pacto pela Saúde de 2006, e, mais recentemente, o Decreto 7.508 de 2011, que regulamentou a Lei n. 8.080 .

De posse desse conjunto de leis, portarias e decretos, se pode afirmar que a regionalização é uma diretriz do Sistema Único de Saúde e um eixo estruturante do Pacto de Gestão, devendo orientar a descentralização das ações e serviços de saúde e os processos de negociação e de pactuação entre os gestores. Essa orientação está presente na própria definição de regionalização adotada pelo Ministério da Saúde, que assim a define:

São recortes territoriais inseridos em espaços geográficos contínuos. Identificá-los é responsabilidade dos gestores municipais e estaduais, tendo como base a existência de identidades culturais, econômicas e sociais, assim como de redes nas áreas de comunicação, infraestrutura, transportes e saúde. Nessas regiões, as ações e serviços devem ser organizados com o objetivo de atender às demandas das populações dos municípios a elas vinculados, garantindo o acesso, a equidade e a integralidade do cuidado com a saúde local (BRASIL, 2006, p.23).

Sob o ponto de vista da educação em saúde, foi a partir da divulgação, pelo Ministério da Saúde, do Pacto pela Saúde, em 2006, que a questão da regionalização ganhou maior visibilidade e importância. Mais especificamente, através das "Diretrizes Operacionais do Pacto pela Saúde 2006 - Consolidação do SUS", com as quais o Ministério da Saúde instituiu que as CIES seriam constituídas por representações dos gestores de saúde, das instituições de ensino que atuam na área da saúde, dos trabalhadores de saúde, e dos movimentos sociais e/ou controle social de uma dada região de saúde; e, ao mesmo tempo, definiu que as CIES constituiriam um espaço político (regional) estratégico na formulação, na condução e no desenvolvimento da Política de Educação Permanente em Saúde, fomentando uma atuação política e social, de indivíduos e instituições sociopolíticas, a partir de um recorte regional. E, nesse sentido, se constituíram em espaços/tempos nos quais se desenvolveram dinâmicas históricas favoráveis à militância política, a partir de sujeitos e de preocupações também locais/regionais. A região não foi institucionalizada como um território de militância, mas passou a ser um importante condicionamento territorial da militância política.

Importante destacar que as mobilizações políticas e sociais e, no interior dessas, a militância no campo da saúde, estiveram presentes desde o período anterior à criação do SUS, na década de 1980. Nesse sentido, pode-se falar de uma militância e da importância da militância no campo da saúde ainda antes de ser criado o SUS, não esquecendo que o Movimento Sanitário foi uma resposta à crise da saúde, mas também um movimento político, ideológico e social, que trouxe consigo a 
bandeira da democratização da própria sociedade brasileira (ESCOREL et al, 2006). Confirmou-se, desse modo, como uma proposta, um projeto e um processo que "ao incidir sobre as relações de poder, transformar-se-ia em um movimento político" (PAIM, 2008, p. 626). O movimento deu uma grande contribuição para o desenvolvimento dos princípios democráticos, além de ter apontado os novos preceitos para o desenvolvimento em relação à saúde como um reconhecimento e obrigação do Estado.

Ao entender a rede regionalizada como um processo de participação social e política, podemos também entender que esse espaço de participação é direcionado a espaços coletivos de engajamento, de protagonismo militante na invenção dos modos de cuidar e gerir os processos de trabalho no campo da saúde, se constituindo num campo fértil para a problematização da atuação não somente dos trabalhadores, mas, também, de diferentes organizações, instituições sociais, movimentos sociais. (CARVALHO, 2002). São vários os fatores que tornam determinadas formas de militância e engajamento possíveis, como pertencimentos sociais, capitais culturais, valores e crenças. Portanto, tornar-se um militante é um processo em que combinam diferentes histórias, tanto das origens sociais, das socializações específicas dos que militam e dos seus lugares na sociedade (OLIVEIRA, 2005).

É interessante distinguir entre quem milita e quem está engajado ou, mesmo, tem apenas uma atuação conjuntural na Comissão de Integração Ensino-Serviço da $28^{a}$ Região de Saúde do Rio Grande do Sul para, a partir dessa definição, compreender qual é o espaço político que os militantes na referida Comissão têm na construção de políticas de educação permanente em saúde na também referida Região de Saúde (REIS, 2007). Nesse sentido, ao se referir aos "militantes da CIES", se faz referência, fundamentalmente, aos que, para além de um engajamento (que pode decorrer de uma participação temporária na Comissão, inclusive pela indicação do poder público municipal), têm uma atuação mais contínua (no tempo e no espaço) na Comissão, mantêm uma "dedicação sistemática" à "causa" educação permanente em saúde. Como afirma Eliana Reis, a militância:

[...] extrapola o sentido mais comum como de qualificação da adesão a uma "causa" (militante) ou de atribuição de um rótulo que define e encerra a sua própria essência ("militância"). [...] tanto as "habilidades" militantes quanto a dedicação à "militância" implicam em processos muito mais amplos. Os mesmos envolvem variáveis como mecanismos de socialização, formas de engajamento, sentidos atribuídos às "causas", modalidades de investimentos oferecidos e de recompensas extraídas dos mesmos [...] (REIS, 2007, p. 11).

Assim, ser militante não implica somente a adesão à determinada causa, nem a atuação regular em determinados espaços sociopolíticos a partir dos quais um 
determinado poder político é mobilizado para a defesa de interesses coletivamente partilhados. A militância implica mais do que isso, remetendo a um modo de vida e à construção de identidade sociopolítica em torno e a partir de uma causa (REIS, 2007; VALVERDE, 1986). Há, portanto de se considerar no presente estudo que a militância que ora se apresenta tem uma materialidade no território (regional). A Região 28 de Saúde do Rio Grande do Sul define não somente espaços de socialização política para os que atuam no campo da saúde como militantes, mas, também, condicionam recortes sociais, políticos, programáticos, ideológicos para as práticas sociais e políticas dos militantes em saúde na Região. O que significa dizer que a atuação dos militantes ocorre (se materializa) através das trajetórias em espaços interinstitucionais públicos e que se dedicam ao debate e à construção de políticas públicas de educação permanente em saúde, nas redes sociais constituídas a partir da participação nesses diferentes espaços. Mas, ao mesmo tempo, se materializa nos desafios, nos conflitos, nas possibilidades de consensos, nas expectativas e nas perspectivas de construção de uma política (regional) de educação permanente em saúde.

\section{A política de educação permanente em saúde na Região 28 de Saúde: uma análise a partir das ações realizadas pela CIES}

Ao analisar a Política de Educação Permanente desenvolvida no período entre 2007 e 2014 na Região 28 de Saúde está se pressupondo que a CIES é um espaço que, por sua própria natureza, discute, propõe, contribui com o planejamento e avaliação da política de educação permanente. Coloca-se como pressuposto, também, que adotar a perspectiva da Educação Permanente não significa apenas mantê-la em pauta no trabalho em saúde, mas também compreender a vivência do trabalho como necessária para a aprendizagem, que se pretende que seja significativa, não somente para os trabalhadores em saúde, mas, também, nas relações que esses estabelecem nos locais, comunidades e espaços onde atuam (FEUERWERKER, 2007).

A integração ensino-serviço é entendida como o trabalho coletivo, pactuado e integrado de discentes e docentes dos cursos de formação na área da saúde com trabalhadores que compõem as equipes dos serviços de saúde (ALBUQUERQUE et al, 2008). Nessa integração, são incluídos, também, os gestores de saúde, tomadores de decisões no contexto dos processos de mudança na formação dos profissionais de saúde. Uma vez que a integração ensino-serviço visa à qualidade de atenção à saúde individual e coletiva, tanto quanto à qualidade da formação profissional e ao desenvolvimento e satisfação dos trabalhadores dos serviços, a constituição da Comissão de Integração Ensino-Serviço (CIES) para sua operacionalidade torna-se estratégia central de execução da política nacional. Não por acaso, essa criação constituiu o primeiro ponto de pauta para deliberação dos 
órgãos colegiados regionais, na atual estruturação da Educação Permanente em Saúde. O conhecimento sobre responsabilidades e atribuições das esferas gestoras em educação permanente em saúde contribui para dar visibilidade e possibilitar uma avaliação dos processos de gestão e de execução das ações em seu nível de atuação. A avaliação dos processos melhor se desenvolve quando as estruturas efetivas de gestão e integração ensino-serviço se constituem e materializam as possibilidades de realização da educação permanente enquanto política pública.

E, enquanto política e estratégia para a mudança das práticas de saúde, a educação permanente deve contar com a participação dos envolvidos: gestores, formadores, trabalhadores da saúde e pessoas militantes em movimentos sociais e no controle social (NICOLETO et al, 2009). Nesse sentido, inclusive, a atual formatação do Colegiado de Gestão Regional e das CIES atendem aos requisitos estabelecidos pela Legislação.

$\mathrm{Na}$ Região 28 de Saúde, as discussões sobre educação permanente em saúde passaram, a partir de 2007, por um processo de transição. Suas ações até então haviam sido desenvolvidas pelos referenciais dos antigos Polos de Educação Permanente em Saúde, articulados por equipes matriciais da macrorregião e compreendendo uma ampla área de abrangência (três regiões sanitárias que formavam a macrorregião dos Vales - a $8^{\mathrm{a}}$, a $13^{\mathrm{a}}$ e a $16^{\mathrm{a}}$ Coordenadorias Regionais de Saúde), composta por cinquenta e dois municípios. A partir de 2007 foi constituído a CIES, cuja Região passou a ser delimitada pelos municípios que já compreendiam a $13^{a}$ Coordenadoria Regional de Saúde (Ata n. 01 da Reunião da CIES da Região 28 de Saúde, de 29 de outubro de 2007), cujo município sede para os encontros de discussão e planejamento das ações da política de educação permanente em saúde foi Santa Cruz do Sul.

No ano de 2007, três meses após a deliberação da Portaria GM/MS 1996/07, foi realizada a primeira reunião da Comissão de Integração de Ensino-Serviço, tendo como pauta a estruturação da CIES na Região 28 de Saúde e formação da composição conforme a resolução 01/07 COGERE/13 ${ }^{a}$ CRS. Na ocasião ficou acordado que os projetos anteriormente formulados pela equipe matricial da Política de Educação Permanente em Saúde Macrorregional seriam reorganizados para sua execução na Região 28 de Saúde. Também foi apresentada a Resolução no 03/07 COGERE $13^{\text {a }} \mathrm{CRS}$, que aprovou os projetos analisados naquela reunião: "A Integralidade e a Saúde Mental: projeto de qualificação da atenção em saúde mental nos âmbitos do cuidado técnico e profissional", "Curso de Formação de Auxiliar de Consultório Dentário" e o "Curso de Especialização Pós-técnico em Saúde Pública"; projetos cujos participantes foram os trabalhadores de saúde, acadêmicos e militantes de movimentos sociais de todos os municípios da região, e que previam a execução das ações através da Universidade de Santa Cruz do Sul (UNISC). Naquela primeira reunião da CIES, realizada em 29 de outubro de 2007, estiveram presentes representantes da $13^{a}$ Coordenaria Regional de Saúde, do Centro de Educação Profissional (CEPRU/UNISC), do Centro de Referência de 
Saúde do Trabalhador - CEREST/VALES e representante da gestão do município de Rio Pardo/RS (Ata n. 01 da CIES da Região 28 de Saúde, de 29 de outubro de 2007).

Após a realização da primeira reunião, no transcurso aproximado de um ano poucos registros foram encontrados sobre as ações da CIES. Foi um período em que se discutiu a composição da Comissão e a necessidade de ajustamento de suas ações diante das alterações induzidas pelas novas portarias da política nacional de educação permanente e resolução do pacto pela saúde. É possível afirmar que os sujeitos sociais que atuavam na CIES não tinham muita clareza do significado das Comissões, definindo suas ações, ainda, com base na experiência dos polos macrorregionais de educação permanente em saúde. O desconhecimento dos gestores e profissionais sobre o real papel da CIES e o próprio conceito de educação permanente, fez com que tanto a execução das ações de forma compartilhada entre todos os municípios quanto a ampliação e a diversificação da composição de seus integrantes fossem retardadas. Cientes disso, inclusive, os atuantes da CIES naquele período, motivados pela Escola de Saúde Pública do Estado do Rio Grande do Sul, procuraram resgatar os sujeitos atuantes no antigo polo de educação permanente em saúde.

O ano de 2008, conhecido como o ano da "implementação", representou um marco na institucionalização da CIES, principalmente no segundo semestre, pois além da visibilidade das ações que se deu a partir de então, o número e a diversidade de representantes na CIES aumentaram. Tanto é assim que na reunião realizada no dia 30 de outubro de 2008 participaram representantes de movimentos sociais, representantes do poder público municipal de Santa Cruz do Sul e de Rio Pardo, representantes da UNISC, representantes da $13^{\mathrm{a}}$ Coordenadoria Regional da Saúde. Aquela reunião teve como pauta a avaliação do processo de execução dos projetos que estavam em andamento: "A Integralidade e a Saúde Mental: projeto de qualificação da atenção em saúde mental nos âmbitos do cuidado técnico e profissional", "Curso de Formação de Auxiliar de Consultório Dentário" e o "Curso de Especialização Pós-técnico em Saúde Pública"; e a elaboração do Plano de Ação Regional da Política de Educação Permanente e Profissional em Saúde da 28 Região para o ano de 2009; por fim e, também, a realização de dois cursos indicados pela própria CIES: um sobre a "Gestão no SUS" e outro na área de "Atenção em saúde mental - 2a edição" (Ata n. 02 da CIES da Região 28 de Saúde, de 30 de outubro de 2008).

É importante registrar, ainda, que durante o ano de 2008 a CIES da Região 28 de Saúde ocupou-se com um trabalho de caracterização da Região, bem como com a discussão sobre possibilidades construídas até então para a gestão da educação e do trabalho em saúde. Daquela reflexão resultou um planejamento de ações, prevendo duas etapas: a) organização de um plano de ação inicial, a partir da escuta dos conselheiros regionais de saúde, dos gestores municipais de saúde, de trabalhadores em saúde da $13^{\mathrm{a}}$ CRS; b) uma discussão ampliada com a 
comunidade em geral dos municípios (segmentos do SUS), a fim de tornar participativo e aberto o processo de planejar a Educação Permanente em Saúde na região. (Ata n. 02 da CIES da Região 28 de Saúde, de 30 de outubro de 2008).

Aquele processo dialógico foi importante, naquele contexto, para que os participantes da CIES acordassem acerca de alguns pontos básicos de ação: a definição de um planejamento coletivo de ações contemplando a realidade da Região; a indicação de alguns eixos de atuação, definidos em uma Resolução (Resolução 077/08 - CIB/RS) sobre Educação Permanente em Saúde, quais sejam: a busca da integralidade da atenção aos usuários do SUS; o processo de trabalho das equipes de saúde; e a participação social na gestão estratégica e participativa (Ata n. 03 da CIES da Região 28 de Saúde, de 27 de novembro de 2008).

Também em 2008, a CIES da Região 28 de Saúde discutiu ações educativas que resultaram no Plano de Ação Regional de Educação Permanente e Profissional em Saúde. Sob a coordenação da Secretaria Estadual da Saúde, um Plano de Ações foi formulado, num processo de discussão que envolveu o Colegiado de Gestão Regional e a CIES/RS. Após a aprovação daquele Plano de Ações, o mesmo foi encaminhado para as CIES regionais. Dentre as ações daquele Plano de Ação Regional de Educação Permanente e Profissional em Saúde constavam:

\footnotetext{
Realização de oficinas que envolvam os atores já qualificados, quer sejam: os tutores e facilitadores de educação permanente, os ativadores de processos de mudança na graduação, os tutores e participantes dos processos de formação da humanização;

Realização de oficinas com atores estratégicos para o SUS no âmbito da Educação Permanente e Educação Profissional em Saúde, articulando os atores dos diversos segmentos - gestão, atenção, instituição formadora e controle social;

Organização de cursos e seminários conforme as necessidades locorregionais;

Criação e fortalecimento de estruturas de gestão da educação e do trabalho em saúde nos municípios e regiões (CIB/RS, 2007. In: Ata n. 03 da CIES da Região 28 de Saúde, de 27 de novembro de 2008).
}

De igual forma, o ano de 2009 foi marcado pelo "fortalecimento", por avanços e desafios para a CIES da Região 28 de Saúde. Desde o seu início, foi desencadeado um processo sistemático de reuniões mensais. Inicialmente, as discussões se preocuparam com a formatação, com a metodologia e com a apresentação dos projetos de Educação Permanente em Saúde para a região. Porém, à medida que os participantes foram se apropriando do assunto, as pautas se expandiram, abrangendo: discussões em oficinas conceituais com experiências municipais; análise de discussão dos projetos de Educação Permanente de acordo com os 
Planos Regionais de Saúde; interlocução permanente com as políticas de saúde implementadas no Estado; discussões com as instituições formadoras; construção de uma proposta de integração com ações municipais; acompanhamento do processo de assinatura do Termo de Compromisso com o Pacto de Gestão; interlocução permanente com os projetos estruturantes do governo do Estado; estratégias de fortalecimento da participação dos movimentos sociais de Educação Permanente em Saúde; e demais demandas surgidas ao longo do caminho, bem como o monitoramento das ações e avaliação. (Ata n. 07 da CIES da Região 28 de Saúde, de 06 de abril de 2009).

Naquele contexto, a CIES passou a ter uma nova configuração, com um número significativo de participantes. Isto ocorreu num ambiente de motivação e de envolvimento dos participantes de todos os municípios com os cursos que estavam em execução naquele período, e também porque vários municípios da região já se faziam representar nas reuniões, cujas pautas eram programadas com antecedência, porém oportunizando espaço para a inclusão espontânea de assuntos ou informes sobre a educação em saúde.

Entre as preocupações da Comissão, naquele período, esteve a de ampliar a compreensão de seus participantes quanto à Portaria norteadora da Política Nacional de Educação Permanente em Saúde, bem como o estudo dos referenciais teóricos relacionados à temática para a elaboração do Plano Regional de Educação Permanente e Profissional em Saúde (ano de 2009). Da mesma forma, por ter ocorrido um processo eleitoral no ano anterior, houve a preocupação em explicar aos novos gestores municipais a Política Nacional de Educação Permanente em Saúde, a fim de garantir que os trabalhadores inscritos nos cursos pudessem continuar suas atividades atreladas aos projetos de 2008, que estavam em fase inicial de execução (Ata n. 11 da CIES da Região 28 de Saúde, de 5 de agosto de 2009).

Naquelas alturas, a Política de Educação Permanente em Saúde já estava sendo assimilada pelos gestores, trabalhadores e outros segmentos dos municípios participantes da CIES. Foi um momento importante, mesmo de construção de identidades entre participantes que começavam a ter presença recorrente na Comissão, indicando a presença de uma militância pela causa educação em saúde que passava por aquele espaço de reflexão (FREIRE, 2006). Na medida em que avançavam as ações (tanto com o planejamento de ações quanto com a realização de oficinas, encontros, seminários) crescia, também, o envolvimento com a CIES, numa dinâmica de atuação que aos poucos foi identificando os participantes daquela Comissão como "o povo da CIES".

Registre-se, também, que durante o ano de 2009 a CIES discutiu vários projetos novos para a Região, dentre os quais: "Estruturação da Comissão de Integração Ensino-serviço (CIES) da 13 $3^{a}$ Coordenadoria Regional de Saúde (CRS)", e "1" Encontro regional de educação permanente e educação profissional de saúde $13^{a}$ 
CRS”, que, após aprovação no Conselho Estadual de Saúde e pela Comissão Intergestora Bipartite/RS, aguardavam os recursos para a sua execução.

No entanto, nenhum daqueles projetos foi executado no ano em vigor, prejudicando, inclusive, o planejamento das ações para o ano de 2010, em virtude, conforme registros das Atas da CIES, da morosidade do Conselho Estadual de Saúde na análise dos projetos (Ata n. 13 da CIES da Região 28 de Saúde, de 08 de outubro de 2009).

Outro evento marcado neste mesmo ano foi a conscientização dos gestores municipais de saúde quanto à importância da formulação de uma política de educação permanente em saúde na Região. Nessa direção, vários e diferentes registros podem ser encontrados nas Atas de reuniões da CIES, relacionados ao diálogo que foi estabelecido com os gestores municipais de saúde da Região, num processo que visava impulsionar nos municípios a discussão e a construção de propostas de ações, a partir da identificação de problemas e das necessidades/prioridades no que diz respeito à formação profissional dos trabalhadores em saúde. (Ata n. 14 da CIES da Região 28 de Saúde, de 9 de novembro de 2009). Naquele contexto, também, a CIES discutiu um projeto denominado VERSUS que, com recursos para sua execução, foi organizado pelo Grupo Estudantil de Trabalho e Educação em Saúde Coletiva (GETESC) Protagonismo Estudantil. A partir daquele projeto se inseriu na pauta de discussão da CIES temas como, por exemplo, a violência, o alcoolismo, drogadição e suicídio (Ata n. 15 da CIES da Região 28 de Saúde, de 7 de dezembro de 2009).

Em 2010, a CIES se "consolidou” enquanto espaço de discussão sobre a educação permanente em saúde e garantiu uma aproximação maior entre os seus diferentes participantes, ainda que houvesse dificuldades na participação dos representantes das gestões municipais, em parte decorrente da descontinuidade na participação desses representantes (o que, algumas vezes, já demonstrava um descaso dos gestores municipais quanto à importância da CIES e, mesmo, da educação permanente em saúde).

Além destas, outras ações foram realizadas conforme os registros (Atas e Relatório de Atividades do Ano) dos encontros dos participantes, indicando que foram várias as discussões e as propostas formuladas pela CIES, dentre as quais se destacaram: a organização para o II Encontro Estadual de Educação Permanente em Saúde; a formação da equipe matricial para avaliação de novos projetos; a avaliação do Projeto VERSUS e do PET-Saúde Vigilância; a análise dos projetos da Escola de Saúde Pública e da Escola Técnica do SUS; a realização de estudos sobre o curso de qualificação para a saúde do idoso; a análise do PET Saúde Mental; a elaboração do Plano Regional de Ações de Educação Permanente e Profissional em Saúde. (Atas n. 23 da CIES da Região 28 de Saúde, de 9 de setembro de 2010). 
Os participantes da CIES vivenciaram, também, momentos de frustração, principalmente em virtude da não efetivação das propostas no período em que se pretendia a sua execução. Tais dificuldades foram relacionadas, pelos participantes da CIES, a dois fatores principais: o prolongado período de tempo decorrido para análise dos projetos nas instâncias de deliberação e pactuação estaduais, principalmente na plenária do Conselho Estadual de Saúde; as dificuldades da Instituição Executora que, por mudanças internas, necessitou reorientar suas ações, priorizando dois projetos: a "Estruturação da Comissão de Integração Ensino-serviço (CIES) da 13 ${ }^{\text {a }}$ Coordenadoria Regional de Saúde (CRS)" e "Oficinas de Sensibilização e Qualificação em Educação Permanente para o Controle Social no SUS” (Ata n. 24 da CIES da Região 28 de Saúde, de 26 de outubro de 2010).

A partir de 2011, alguns indicadores demonstravam necessidades de atenção equilibrada para as áreas rural e urbana, envolvendo mudança de perfil de formação/qualificação do profissional de saúde, visando à prevenção e promoção da saúde (BUSS, 2000). Essa nova formação, no entendimento dos participantes da CIES, precisava estar voltada para ações que contemplassem o trabalho com comportamentos das pessoas em relação à própria saúde, bem como estratégias coletivas de melhoria das condições de vida. Além disso, enfatizavam os participantes da CIES, que tais ações deveriam ser realizadas tanto em instituições de ensino, quanto na rede de saúde, durante o processo de trabalho, de gestão e de controle social (Ata n. 30 da CIES da Região 28 de Saúde, de 5 de maio de 2011).

Este, então, se constituiu num dos principais desafios da CIES durante o ano de 2011, pois passou pela organização da formação/qualificação integrando as ações de capacitação técnica e as reflexões sobre o processo de trabalho, em dois movimentos: por um lado, o fortalecimento da Educação Permanente em Saúde em cada município; por outro, a articulação intermunicipal, além de projeto de "Contratação de instituição de ensino superior para desenvolver pesquisa com objetivo de mapear a realidade dos processos de gestão do trabalho e de educação permanente em saúde dos trabalhadores que atuam no SUS, no âmbito da $13^{\text {a }}$ CRS” (LOPES, 2007). Ao mesmo tempo foi dado o primeiro passo em direção à Agenda Positiva do Departamento de Gestão e da Regulação do Trabalho em Saúde, uma agenda visualizada como uma possibilidade de realização de ações voltadas à organização dos trabalhadores de saúde na efetiva gestão do trabalho (Ata n. 31 da CIES da Região 28 de Saúde, de 09 de junho de 2011).

Através do Projeto de Estruturação da CIES da Região 28 de Saúde foi contratado um consultor/apoiador técnico e um apoiador administrativo (Ata n. 30 da CIES da Região 28 de Saúde, de 05 de maio de 2011) ficando garantido, além de melhores condições para o aprofundamento do debate em torno da educação permanente em saúde, a presença de um profissional, com carga horária disponível para a Comissão, assumindo diferentes funções, entre as quais a de secretariar reuniões, buscar e catalogar contatos, contatar e convidar os 
participantes para as reuniões, divulgar eventos, organizar material da Comissão e documentos relacionados à educação permanente, entre outras atividades (Ata n. 30 da CIES da Região 28 de Saúde, de 05 de maio de 2011).

Estas iniciativas objetivaram fortalecer a CIES, de forma a dar continuidade em suas discussões e ações, e se fizeram necessárias também pela não possibilidade, naquele momento, de haver maior apoio institucional de alguma instância da $13^{\mathrm{a}}$ Coordenadoria Regional de Saúde. É importante registrar, também, que o referido fortalecimento possibilitou uma ação mais orgânica da CIES junto às gestões municipais, através de incentivos e de orientação para a execução da política de educação permanente em saúde nos municípios, em especial através dos NUMESC - Núcleos Municipais de Saúde Coletiva (Ata n. 33 da CIES da Região 28 de Saúde, de 10 de agosto de 2011).

Importante o registro, também, de uma reunião conjunta da Comissão Intergestores Regionais de Saúde e a CIES, realizada em dezembro de 2011, ocasião na qual foram indicadas (pelos gestores e pelos trabalhadores em saúde) algumas áreas prioritárias para a ação de educação em saúde, dentre as quais: saúde mental, urgência-emergência; fortalecimento dos espaços de gestão, qualificação de pronto-atendimento e organização da SAMU; fortalecimento da Rede de cuidados aos usuários de álcool, crack e outras drogas, da Rede de prevenção à violência, da Rede de cuidados e de prevenção do câncer, da Rede de atenção às urgências, da Rede de atenção psicossocial e da Rede cegonha; qualificação dos profissionais de ensino médio e técnico que atuam no atendimento direto ao usuário; solidificação dos Núcleos Municipais de Educação em Saúde Coletiva (Ata n. 37 da CIES da Região 28 de Saúde, de 12 de dezembro de 2011).

A definição desse conjunto de áreas indicadas no parágrafo anterior tornou-se importante, inclusive, no processo de discussão que ocorreu ainda em 2011 sobre o Plano de Ação Regional de Educação Permanente e Profissional em Saúde para o ano de 2012. Discussão aquela que impulsionou a criação de um Grupo de Trabalho (GT) para o levantamento de dados da região e para a construção da pesquisa de avaliação de trabalho em saúde - pesquisa que, planejava-se, seria executada pelo Grupo de Educação e Pesquisa em Saúde da UNISC (Ata n. 35 da CIES da Região 28 de Saúde, de 11 de outubro de 2011).

$\mathrm{O}$ ano de 2012 ficou marcado por avanços e por expectativas quanto à consolidação da Política de Educação Permanente em Saúde, pois houve uma redefinição na sua condução pela CIES. Com rumos mais solidificados, foram tomadas tarefas como prioritárias nessa nova configuração: a manutenção, a disseminação e o fortalecimento da própria CIES, identificada como espaço de fundamental importância para propiciar a continuidade das estratégias e das ações planejadas, tanto no âmbito dos municípios quanto no âmbito regional (Ata n. 40 da CIES da Região 28 de Saúde, de 14 de março de 2012). 
Merece destaque, também, a maior aproximação da UNISC-Universidade de Santa Cruz do Sul com a CIES, o que resultou na ampliação de atividades conjuntas como, por exemplo, a realização de uma pesquisa, a formação de um Grupo de Trabalho para a operacionalização da pesquisa nos treze municípios da Região (pesquisa realizada com o objetivo de identificar o processo de gestão do trabalho e de educação permanente em saúde dos trabalhadores vinculados ao SUS no âmbito da Região). A referida aproximação foi intensificada, inclusive, em virtude de projetos ministeriais como, por exemplo, o "Pró-Saúde", o "Pet-Saúde Vigilância", o "Pet-Saúde Mental", o "Pet-Saúde Redes de Atenção", e o "PetSaúde Vigilância em Saúde II". A realização desses projetos, conforme os editais do Ministério da Saúde, pressupunha a participação da CIES para a disseminação, monitoramento e avaliação junto aos serviços de saúde da Região (bem como da participação da Comissão Intergestores Regionais, para pactuação e aprovação dos projetos em nível regional). (Ata n. 43 da CIES da Região 28 de Saúde, de 13 de junho de 2012).

Ao longo do ano de 2012, além dos temas já mencionados, vários outros foram objetos das discussões e dos estudos realizados pelos participantes da CIES. Mas, dentre todos esses temas, três ganharam maior evidência nas reuniões da Comissão: os "Núcleos Municipais de Educação em Saúde Coletiva", o "Projeto Estratégia de Mobilização do Controle Social da $13^{\mathrm{a}}$ CRS" e os "Recursos Financeiros necessários para a execução dos projetos”.

Em relação aos Núcleos Municipais de Educação em Saúde Coletiva, os mesmos foram criados e instituídos pela Resolução no 14/2012, de 3 de abril de 2012. Essa discussão avançou significativamente na Região 28 de Saúde, seja através da realização de seminários, eventos de divulgação, seja através de gestões junto aos poderes públicos municipais. Ainda que a discussão promovida não tenha resultado na criação dos referidos núcleos em todos os municípios da Região, pelo menos todos os municípios ficaram conscientes da Proposta resultante da Resolução no 14/2012.

Ao final do mesmo ano, já haviam sido criados nove Núcleos Municipais de Educação em Saúde Coletiva, expressão do significativo debate promovido (com a participação efetiva da CIES) na Região 28 de Saúde. Ocorreu uma intensa movimentação entre os profissionais e gestores da saúde, tanto como facilitadores quanto como aprendizes, na busca por uma transformação da política pública de saúde nos espaços de circulação dos saberes e dos projetos de consolidação do SUS (QUINTANA, 2016). (Ata n. 48 da CIES da Região 28 de Saúde, de 14 de novembro de 2012).

Quanto ao projeto Estratégia de mobilização do controle social da $13^{\mathrm{a}} \mathrm{CRS}$, que objetivava apresentar o SUS à população de forma diferenciada, dinâmica e compreensível, foram realizadas várias Oficinas de Sensibilização, com representantes de trabalhadores, de gestores e de movimentos sociais dos 
municípios da Região. A UNISC foi parceira no projeto, disponibilizando o espaço físico para as atividades então realizadas. Nas oficinas, o projeto foi apresentado com o intuito de discutir as estratégias de divulgação do SUS, bem como da rede de serviços, para os usuários dos treze municípios da Região. A decisão recaiu, então, sobre uma forma artístico-cultural, além da produção de informativos (tipo folder/encarte de jornais). (Ata n. 44 da CIES da Região 28 de Saúde, de 11 de julho de 2012).

Além das oficinas indicadas, foram realizadas oficinas com o grupo de cultura " $\mathrm{O}$ CUBO", da UNISC, a partir das quais foi organizada uma apresentação (de teatro musical) relatando a criação do SUS e "como todos usam o SUS". A apresentação ocorreu, então, nos municípios de Mato Leitão, de Santa Cruz do Sul e de Rio Pardo. No entanto, para estas apresentações, participaram também usuários dos municípios contíguos ao da apresentação, mobilizados com antecedência ao evento (Ata n. 46 da CIES da Região 28 de Saúde, de 12 de setembro de 2012).

Em relação aos recursos financeiros necessários para a execução dos projetos, se observou por parte da CIES que após a troca do governo estadual (2010) o processo ficou mais lento e complexo, gerando a necessidade da criação de um regimento interno da CIES/RS (estadual), além de dificuldades internas para o funcionamento das reuniões mensais. Tal processo se refletiu no trabalho das CIES regionais, pois não se tinha uma clareza de condução da política em nível estadual.

Os recursos para o financiamento da educação permanente e profissional em saúde, na Região 28 de Saúde, que desde 2007 estavam alocados pelo Fundo Municipal de Saúde, do município de Santa Cruz do Sul (município sede da região), devido a diversos fatores - dentre eles o fato de que muitos municípios da Região não terem aderido e assinado o Pacto pela Saúde -, passou a ser alocado no Fundo Estadual de Saúde do Rio Grande do Sul, o que criou maiores dificuldades para o acesso dos mesmos (Ata n. 44 da CIES da Região 28 de Saúde, de 11 de julho de 2012).

Note-se que a questão dos recursos financeiros está vinculada à própria preocupação, no âmbito da CIES, com os escassos recursos com os quais se podem contar para a execução dos projetos que são planejados para a Região de sua atuação.

Lado a lado com os debates implicados aos três temas indicados como temas recorrentes nas reflexões realizadas no âmbito da CIES no ano de 2012, outros projetos foram discutidos durante aquele ano, buscando parcerias com outras instituições e com a própria Secretaria de Gestão e do Trabalho em Saúde. Dentre os projetos planejados durante 2012, registram-se os seguintes: cadernos de alimentação e de nutrição; intersetorialidade e saúde mental; qualificação de grupos-território para a Promoção de Saúde na Escola; I Encontro Regional de Educação Permanente em Saúde; Vídeo sobre a política de gestão do trabalho e 
Educação Permanente em Saúde na região; projeto de descentralização das ações de gestão, trabalho e da educação na saúde; projeto de pesquisa sobre saúde do trabalhador, em princípio um projeto que seria executado pelo Centro Regional de Saúde do Trabalhador (CEREST/Vales). (Ata n. 44 da CIES da Região 28 de Saúde, de 11 de julho de 2012).

Por fim, também em 2012, a CIES esteve envolvida na organização do Plano de Ação Regional de Educação Permanente e Profissional para o ano de 2013, optando por trabalhar em um projeto amplo que contemplasse "vários projetos" ao mesmo tempo, englobando as necessidades elencadas de redes prioritárias e temáticas a partir da Política de Gestão do Trabalho, com vistas a potencializar a gestão do trabalho na região (rede cegonha, urgência e emergência, rede psicossocial, doenças crônicas não transmissíveis) e o envolvimento de profissionais da saúde. (Ata n. 48 da CIES da Região 28 de Saúde, de 14 de novembro de 2012).

Durante os anos de 2013 e 2014, diversas ações foram desenvolvidas pela CIES, muitas delas em parceria com o NURESC/13 ${ }^{a}$ CRS, os NUMESCs e com instituições de ensino. Dentre elas se destacaram os seguintes projetos: Mapeamento e Fortalecimento do controle Social; Diversidades dos Sujeitos e da Promoção da Saúde no SUS da Região 28 de Saúde; Mapeamento e Fortalecimento do controle Social; Diversidades dos Sujeitos e da Promoção da Saúde no SUS da Região 28 de Saúde; os "Seminários Redes de Atenção à Saúde na Região 28 de Saúde / RS"; o "Edital do Ministério da Saúde para Pró e PetSaúde", por diversas vezes realizado de forma regional pela UNISC; o terceiro ano da Residência Integrada em Saúde da Escola de Saúde Pública/RS (R3/RIS/ESP), realizado no município de Venâncio Aires, a qual desenvolveu ações de Gestão e Educação em Saúde Coletiva, através de intervenção interdisciplinar, analítica, crítica, investigativa, resolutiva e propositiva, em âmbito técnico, administrativo e político do SUS.

A Interlocução com as instituições formadoras (e, no caso específico, com a UNISC) tem tido considerável relevância, embora, por princípios éticos e metodológicos, a Política de Educação Permanente em Saúde não seja aprisionável em formatos acadêmicos, podendo e devendo buscar e reconhecer outros modos de encaminhar ações de educação em saúde (SARRETA, 2009). A interlocução com as universidades é imprescindível, pois estas também comportam um modo de intervenção e, principalmente, representam "portas de entrada" para um diálogo que busca mudanças já na formação (acadêmica) dos profissionais de saúde, numa perspectiva de afirmação dos valores do SUS.

Essas discussões foram aprofundadas na relação com as instituições formadoras para além do fluxo da oferta de cursos, o que também já vinha sendo trabalhado na CIES, anualmente, em especial no trabalho de elaboração dos Planos de ação Regional de Educação Permanente e Profissional de Saúde, quando são levantadas 
as necessidades locorregionais e o planejamento é realizado de forma participativa e por identificação de problemas.

Portanto, mesmo que através das ações que foram desenvolvidas pela e na CIES, o relato das ações que foram executadas durante o período de 2007 e 2014 é indicativo de um processo histórico emergente, mas, também, em desenvolvimento, da discussão, provocada pelas políticas nacionais, sobre a importância da mobilização regional em prol de uma política (também regional) de educação permanente em saúde. Pode-se afirmar, nesse sentido e a partir do relato das ações desenvolvidas na CIES, que a educação permanente em saúde ganhou visibilidade na Região 28 de Saúde no período analisado.

Entre seus vários aspectos, esta análise teve uma importância pelo conhecimento de outros espaços intergovernamentais, políticos e técnicos em que ocorrem o planejamento, a negociação e a implementação das políticas públicas e, portanto da própria CIES, pois mesmo sendo ela constituída por funções consultivas na construção da política pública de educação permanente em saúde, sua importância neste sentido se coloca no campo da mobilização, da discussão, da provocação para a formulação de políticas, do acompanhamento e da própria fiscalização da política regional de educação permanente em saúde, integrando representações tanto do governo quanto de diferentes segmentos da sociedade civil organizada. Segmentos esses que tiveram participação na discussão e implementação dos Núcleos Municipais de Educação em Saúde Coletiva - NUMESC, tornando-os um espaço de diálogo, reflexão e ação fundamental. Haja vista a responsabilidade que os sujeitos militantes possuem na consolidação de propostas de Educação Permanente em Saúde a partir da preocupação não somente no que diz respeito ao cumprimento das determinações legais, relacionadas às indicações da própria legislação no desenho institucional desta política, mas, principalmente, no sentido de "manter acesa" a discussão sobre uma política regional de educação permanente em saúde na Região 28 de Saúde, objeto deste estudo.

\section{Considerações Finais}

O relato das atividades da CIES na Região 28 de Saúde (RS) é revelador de duas questões importantes na construção de políticas públicas de educação permanente em saúde no Brasil: a) o processo de regionalização dessas políticas ainda é incipiente, requerendo maior adesão e comprometimento dos poderes públicos municipais; b) a CIES, embora instituída pela legislação como um espaço apenas consultivo no âmbito das Regiões de Saúde, pode se colocar como um importante espaço de militância e, inclusive, de execução de políticas regionais de educação permanente em saúde. 
Em relação à primeira questão, é importante destacar, como foi registrado neste artigo, que, no caso da Região 28 de Saúde (RS), a CIES assumiu um papel de protagonismo na discussão e, mesmo, na execução de ações de educação permanente em saúde. Os poderes públicos municipais, como indicados, não somente mostraram pouca adesão em discussões estratégicas para a construção das políticas (Planos Anuais de Ação), como, também, mostraram-se, muitas vezes, refratários na construção dos Núcleos Municipais de Educação em Saúde Coletiva (NUMESCs), afinal núcleos de competência municipal, mas que, no caso da Região 28 de Saúde, avançaram a partir das reflexões e das pressões que os participantes da CIES fizeram junto às administrações municipais.

Daí decorre, então, a segunda questão, relacionada à importância da CIES como espaço de militância no campo da educação permanente em saúde. Embora tenha caráter consultivo, a CIES tem uma representação ampliada, contemplando não apenas gestores municipais, mas, também, representantes da sociedade civil organizada. O que se pode perceber, a partir da experiência histórica da CIES na Região 28 de Saúde (RS), é que os diferentes movimentos sociais e as diferentes instituições comprometidas com esse campo das políticas públicas (e regionais) de saúde, na medida em que perceberam na Comissão um espaço importante de discussão e, mesmo, de execução de ações, passaram a ter uma atuação mais orgânica na Comissão, potencializando esse espaço enquanto um espaço político e de militância na construção das políticas regionais de educação permanente em saúde. A região, através da atuação na CIES, foi transformada num "território de militância”, espaço/tempo a partir do qual indivíduos, coletividades, movimentos sociais, instituições sociais, mesmo governos municipais, passaram a se mobilizar, agir politicamente com o intuito de que seus interesses pudessem ser representados na construção das políticas (regionais) de educação permanente em saúde.

\section{Referências}

ALBUQUERQUE, Verônica Santos et al. A integração ensino-serviço no contexto dos processos de mudança na formação superior dos profissionais da saúde. Rev. Bras. Educ. Méd. Rio de Janeiro, v. 32, n. 3, p. 356-362, 2008.

BATISTA, Karina B. Calife; GONÇALVES, Otília S. Janeiro. Formação dos Profissionais de Saúde para o SUS: significado e cuidado. Saúde e Sociedade, São Paulo, v. 20, n. 4, p. 884-899, 2011.

BRASIL. Casa Civil. Decreto nº7. 508, de 28 de junho de 2011. Dispõe sobre as diretrizes para a implementação da Política Nacional Presidência da República. Diário Oficial [da] República Federativa do Brasil, Brasília, DF, 29 jun. 2011. 
Disponível em: <http://www.planalto.gov.br/ccivil_03/_ato20112014/2011/decreto/D7508.htm>. Acesso em: 06 out. 2016.

BRASIL. Lei Orgânica da Saúde, No 8.080 de 19 de setembro de 1990, dispõe sobre as condições para a promoção, proteção e recuperação da saúde, a organização e o funcionamento dos serviços correspondentes, e dá outras providências. 1990a Brasília-DF.

BRASIL. Ministério da Saúde. Portaria GM/MS no 198, de 13 de fevereiro de 2004. Institui a Política Nacional de Educação Permanente em Saúde - como estratégia do Sistema Único de Saúde para a formação e o desenvolvimento de trabalhadores para o setor e dá outras providências. Diário Oficial [da] República Federativa do Brasil, nº 32/2004, seção I, Brasília, DF, 13 fev.2004. Disponível em:<https://www.nescon.medicina.ufmg.br/biblioteca/registro/referencia/0000 001427>Acesso em: 06 out.2016.

BRASIL. Ministério da Saúde. Portaria GM/MS no 399, de 22 de fevereiro de 2006. Aprova as Diretrizes Operacionais do Pacto pela Saúde. Diário Oficial [da] República Federativa do Brasil, Brasília, DF, 23 fev.2006. Disponível em:<http://www.cremesp.org.br/library/modulos/legislacao/versao_impressao. php?id=6620Acesso em: 07 out. 2016.

BRASIL. Ministério da Saúde. Portaria GM/MS no 1.996/07, de 20 de agosto de 2007. Dispõe sobre as diretrizes para a implementação da Política Nacional de Educação Permanente em Saúde e dá outras providências. Diário Oficial [da] República Federativa do Brasil, Brasília, DF, 22 ago. 2007. Disponível em:<http://amazonia.fiocruz.br/arquivos/category/66-esp-educacaopermanente-gestao-regionalizada-sus?download=1034:>Acesso em: 07 out. 2016.

BRASIL. Presidência da República, Casa Civil, Subchefia para Assuntos Jurídicos. Constituição da República Federativa do Brasil, Brasília, DF, 05 out. 1988.

Disponível em:<http://www.planalto.gov.br/ccivil_03/constituicao/constituicaocompilado.h tm> Acesso em: 06 out. 2016.

BUSS, Paulo Marchiori. Promoção da Saúde e qualidade de vida. Ciência e Saúde Coletiva, Rio de Janeiro, v.5, n.1, p.163-177, 2000.

CARVALHO. Maria do Carmo A. Albuquerque. Participação social no Brasil hoje. São Paulo: Editora: Instituto Pólis, 2002. (Pólis Papers) 
ESCOREL, Sara et al. As Origens da Reforma Sanitária e do SUS in: LIMA, Nísia Trindade et al. Saúde e Democracia História e Perspectivas do SUS, parte III, Fiocruz, Rio de Janeiro, 2006.

FEUERWERKER, Laura C.M. Educação na saúde: educação dos profissionais de saúde - um campo de saber e de práticas sociais em construção. Revista Brasileira Educação Médica, v. 31, n. 1, p. 3-4, 2007.

FREIRE, Paulo. Pedagogia da autonomia: saberes necessários à prática educativa. 33 ed. São Paulo: Paz e Terra, 2006.

LOPES, Sara R.Souto et al. Potencialidades da educação permanente para a transformação das práticas de saúde. Comunicação em Ciências Saúde, Brasília, v.2, n.18, p.147-155, abr.2007.

NICOLETO, Sônia Cristina Stefano et al. Polos de educação permanente em saúde: uma análise da vivência dos atores sociais no norte do Paraná. Interface, Botucatu/SP, v. 13, n. 30, p. 209-219, 2009.

NÚCLEO REGIONAL DE EDUCAÇÃO EM SAÚDE COLETIVA. Atas de Reuniões da CIES da Região 28 de Saúde, Livro 01. 13 ${ }^{a}$ Coordenadoria Regional de Saúde, Santa Cruz do Sul-RS. 2016.

OLIVEIRA, Wilson José Ferreira de. Paixão pela Natureza: Atuação profissional e participação na defesa de causas ambientais no Rio Grande do Sul entre 1970 e início dos anos 2000. 2005. Tese (Doutorado em Antropologia) Universidade Federal do Rio Grande do Sul, Rio Grande do Sul, 2005.

PAIM, Jairnilson Silva. A reforma sanitária brasileira e o Sistema Único de Saúde: dialogando com hipóteses concorrentes. Physis Revista de Saúde Coletiva, Rio de Janeiro, 18 [ 4 ]: 625-644, 2008, p. 626

QUINTANA, Pedro Brito; ROSCHKE, Maria Alice Clasen. Educação permanente processo de trabalho e qualidade de serviço na saúde. Tradução livre por Fernando Cardoso Nascimento - Jornalista MT-DRT 05489. Disponível em: www.escoladesaude.pr.gov.br/arquivos/File/textos\%20eps/ último acesso em 22 de fevereiro de 2016.REIS, Eliana Tavares dos. Contestação, engajamento e militantismo. Da luta contra a ditadura à diversificação das modalidades de intervenção política no Rio Grande do Sul. 2007. Tese (Doutorado em Ciência Política) - Universidade Federal do Rio Grande do Sul, Porto Alegre/RS, 2007. 
RIO GRANDE DO SUL. Colegiado de Gestão Regional da $13^{\mathrm{a}}$ CRS. Resolução $\mathbf{n}^{\mathbf{0}} \mathbf{0 1 / 0 7}$. Secretaria Estadual de Saúde, 06 de novembro de 2007a.

RIO GRANDE DO SUL. Colegiado de Gestão Regional da $13^{\mathrm{a}}$ CRS. Resolução $\mathbf{n}^{\mathbf{0}} \mathbf{0 3 / 0 7}$. Secretaria Estadual de Saúde, 06 de novembro de 2007b

RIO GRANDE DO SUL. Secretaria Estadual de Saúde. CIB. Distribuição das Comissões Permanentes de Integração Ensino Serviço (CIES). CIB/RS. Resolução no 143/07. Porto Alegre (RS): SES; 2007c.

RIO GRANDE DO SUL. Secretaria Estadual de Saúde. CIB/RS Resolução no 45/07, de 16 de maio de 2007, Porto Alegre, RS, 2007d.

RIO GRANDE DO SUL. Secretaria Estadual de Saúde. CIB/RS Resolução no 170/07 de 19 de setembro de 2007, que Define as atribuições do Colegiado de Gestão Regional (COGERE), no âmbito da Educação Permanente em Saúde, Porto Alegre, RS 2007c.

RIO GRANDE DO SUL. Secretaria Estadual de Saúde. CIB/RS Resolução no 77/08 de 06 de abril de 2008, Porto Alegre, RS 2008.

RIO GRANDE DO SUL. Secretaria Estadual de Saúde. CIB/RS Resolução no 555/12 de 19 de setembro de 2012, altera a configuração e a quantidade de Regiões de Saúde no Rio Grande do Sul, e institui as Comissões Intergestores Regionais - CIR, Porto Alegre, RS, 2012

SARRETA, Fernanda Oliveira. Perspectivas da Educação Permanente em Saúde: Educação permanente em saúde para os trabalhadores do SUS [online]. São Paulo: Editora UNESP; São Paulo: Cultura Acadêmica, 2009.

VALVERDE, Monclar. Militância e poder (Balizas para uma genealogia de militância). 1986. 309 f. Dissertação (Mestrado em Ciências Humanas) Departamento de Historia do Instituto de Filosofia e Ciências Humanas, UNICAMP, Campinas, 1986. 
Endereço para correspondência:

Maria Raquel Pilar Steyer - raquel.steyer@gmail.com Travessa Rodolfo Moreira de Souza, 59 - Centro 96640000 - Rio Pardo/RS, Brasil

Telefone: (51) 37317265

Marco AndréCadoná - mcadona@unisc.br Av. Independência, 2293 - Departamento de Ciências Humanas - Bloco 3 sala 303 - Universitário 96815900 - Santa Cruz do Sul/RS, Brasil Telefone: (51) 37177300 Ramal: 7369

Leni DiasWeigelt_lenid@unisc.br Avenida Independência, 2293 - Universitário 96815-900 - Santa Cruz do Sul/RS, Brasil Telefone: (51) 37177469 